\title{
Impregnation Technique Provides Corrosion Protection to Grouted Post-Tensioning Tendons
}

\author{
David Whitmore ${ }^{1 *}$, Ivan Lasa ${ }^{2}$ \\ ${ }^{1}$ Vector Corrosion Technologies, Winnipeg, Manitoba, Canada \\ ${ }^{2}$ Florida Department of Transportation, Gainesville, Florida, United States
}

\begin{abstract}
Thousands of bridge structures rely on grouted post-tensioning (PT) tendons. Problems with grouting techniques and grout materials have resulted in bridges with grout voids, chloride contaminated grout and soft grout. These problems have promoted corrosion and failure of posttension tendons, some within 6 to 17 years of service. The Florida Department of Transportation (FDOT) has spent more than $\$ 55$ million (USD) repairing 11 post-tensioned bridges to date. A cost-effective corrosion mitigation technique has been developed to minimize the corrosion of PT tendons and extend the service life of bridges which have grouting issues. This paper describes the development and implementation of this technique on grouted PT bridges.
\end{abstract}

\section{Post-tensioning grout problems}

Bonded post-tensioned structures are at increased risk of corrosion and failure of the tendons when there are defects in the installed grout. The most common grout problems (defects) include:

\subsection{Voids}

Voids may be present as a result of grout leakage or incomplete filling of the ducts. More commonly, voids are a result of grout bleed where excess water floats to the top of the grout resulting in a pocket of water or a void if the water is re-absorbed into the grout. Grout bleed was a normal occurrence and typically ranged between 3 and $5 \%$ of total grout volume when standard cement / water grout was used.

\subsection{Variations in grout properties}

Grout is intended to provide a uniform, protective environment around post-tension strands. Variations in grout properties can create differences in corrosion potentials which can initiate and sustain corrosion. A variation in properties such as $\mathrm{pH}$, density, porosity and chemical composition (eg. chlorides, sulfates) can result in corrosion.

Excess water used with prepackaged grouts can also result in segregation and the creation of porous and / or soft grout with a different chemical composition than the remainder of the bulk grout. Excess water in cement / water grouts can result in a layer of porous, soft, chalky grout along the interface of the grout and the bleed water void. These conditions can hasten corrosion initiation without the need for other environmental contaminants.

\subsection{Soft grout}

High water-cement ratio can result in soft grout which does not harden. Florida Department of Transportation defined soft grout as grout which can be penetrated more than $1 / 16$ " by an awl with 10 to 15 pounds of force (1).

\subsection{Chloride-contaminated grout}

The detrimental effect of chlorides and their ability to initiate corrosion is well known. Despite this knowledge and the desire of owners, engineers and suppliers to avoid chlorides, chloride contamination may still occur. Chloride contamination can occur in a number of ways, including:

- Exposure to chlorides in the environment.

o Seawater or salt spray may come in contact with the steel strands or may accumulate in the ducts during construction.

o Chlorides may accumulate over time if the structure is exposed to seawater or de-icing salt contaminated water. Susceptible areas include grout voids, and tendons near joints and cracks in the structure.

- Chloride contamination of the grout.

- Grout can be contaminated through the use of mix water which contains chloride.

o In some cases, the grout itself may contain chlorides.

* Corresponding author: davidw@vector-corrosion.com 


\section{Investigation of grouted PT structures}

There are several testing methods that can be used for investigating the condition of grouted PT tendons, such as:

- Location of PT strands using GPR.

- Visual inspection of PT tendons in openings (test pits).

- Grout voids can be detected using sonic/ultrasonic techniques.

- Potential for corrosion can be measured using the moisture-based corrosion evaluation technique.

- Chloride analysis of PT grout samples.

- Chemical and pH (carbonation) testing of grout samples.

- Identification of broken PT strands or wires using magnetic methods.

The effectiveness of each method depends on the type of structure, the location of the tendons, and the specific defect to be identified.

\subsection{The solution}

The Post-Tech PTI Impregnation system is an innovative technique which has been developed to mitigate corrosion caused by these problems. This system utilizes the interstitial spaces between the wires of each strand (Figure 1) as a longitudinal capillary along the length of the strand.

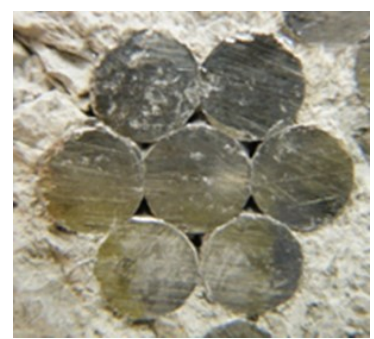

Fig. 1. Interstitial spaces between wires

The impregnation material is introduced into the tendon and is able to travel the length of the tendon as illustrated in Figure 2 and Figure 3.

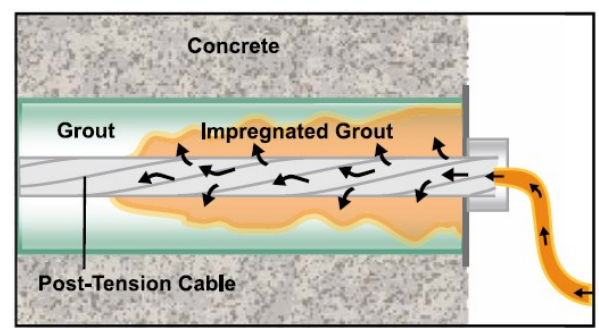

Fig. 2. Impregnation from the end of a PT tendon.

The impregnation material present within the strand is able to seep between the wires into the surrounding grout as shown graphically in Figure 2 and Figure 3 as well as photographically in Figure 4.

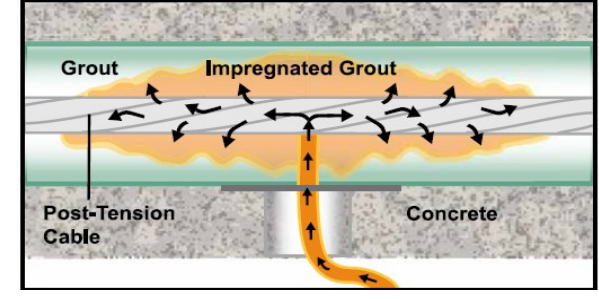

Fig. 3. Impregnation from an intermediate location.

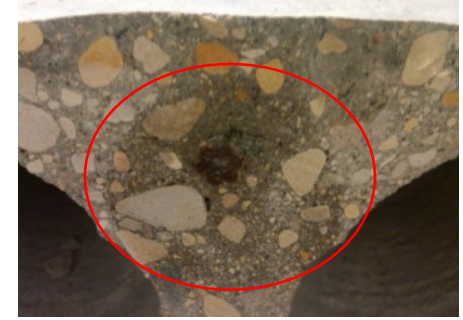

Fig. 4. Concrete surrounding a single seven wire strand shows a radial pattern of Impregnation.

The corrosion impregnation material forms a film on exposed steel surfaces such as steel strands which are exposed in grout voids. The impregnation material also soaks into the grout adjacent to the strand and improves the resistance of the grout to moisture and corrosion.

\section{Florida DOT}

Florida DOT has a number of post-tensioned bridges which have experienced corrosion of post-tension tendons as a result of grout issues as described above.

To investigate the capabilities of the Post-Tension Impregnation technique, Florida DOT has performed:

1. Laboratory Confirmation, and

2. Field Projects.

\subsection{Laboratory confirmation}

\subsection{Treated and untreated bare strand samples exposed to salt spray}

The corrosion resistance of the impregnation material was first tested on individual prestressing strands. The test consisted of application of the impregnation material onto the surface of a prestressing strand and subjecting treated and untreated specimens to periodic $5 \% \mathrm{NaCl}$ salt spray application. As shown below, the test provided a dramatic visual difference between treated and untreated strands.

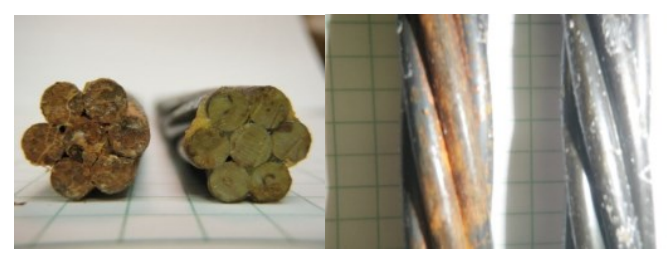

Fig. 5. Untreated and treated strands during and after periodic salt spray application. 


\subsection{Impregnated and non-impregnated bridge tendon samples exposed to salt-fog and salt water ponding}

FDOT completed a laboratory evaluation on treated and untreated post-tension tendon sections which had been removed from the Ringling Bridge in Sarasota, FL. These tendons had been removed due to corrosion failures which had occurred during the warranty period. The tendons had been grouted using pre-packaged Sikagrout 300 PT grout.

In this evaluation, one set of three treated and three untreated samples were exposed in a salt-fog chamber to $5 \%$ sodium chloride $(\mathrm{NaCl})$ salt-fog for 5000 hours as shown in Figure 6. Specimens were autopsied at the end of the accelerated corrosion test and the PT strands were removed and inspected. PT strands inside treated specimens had little or no corrosion (Figure 7) compared to PT strands in untreated control samples (Figure 8).

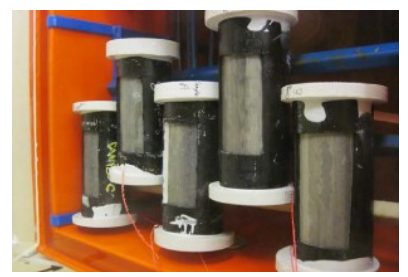

Fig. 6. Treated and untreated test specimens placed in the salt fog chamber.

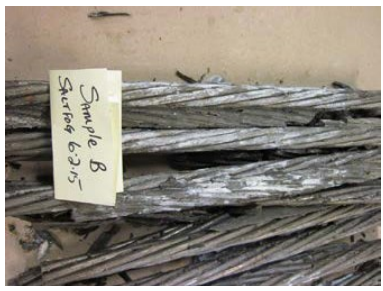

Fig. 7. Treated sample showing no corrosion.

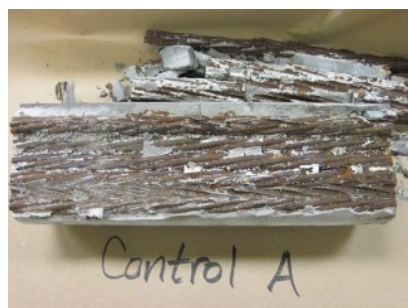

Fig. 8. Untreated sample showing corrosion on $100 \%$ of strands

The second set of three treated and three untreated control samples were ponded with salt water $(3 \% \mathrm{NaCl})$ (Figure 9). Specimens were autopsied after 3750 hours of exposure. Again, PT strands inside treated specimens experienced much less corrosion than untreated specimens (Figure 10 and Figure 11).

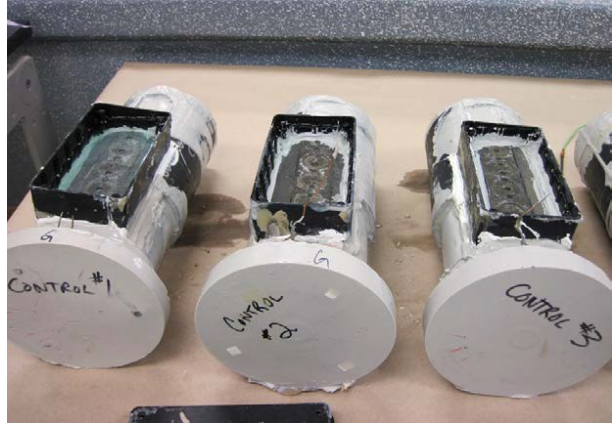

Fig. 9. Treated and Untreated Test Specimens Ponded with 3\% Salt Water $(\mathrm{NaCl})$

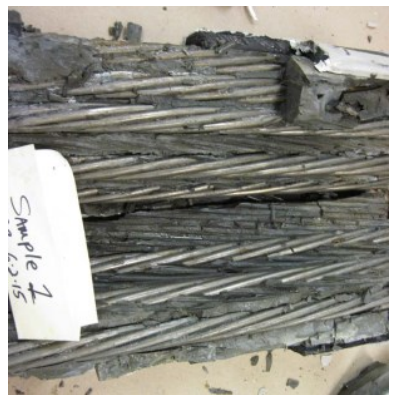

Fig. 10. Treated sample showing no corrosion

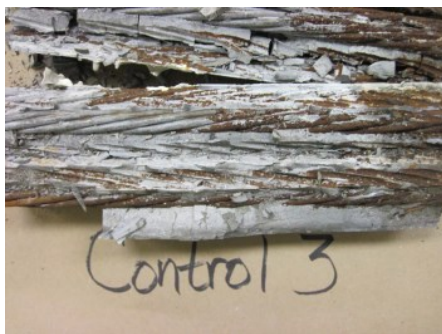

Fig. 11. Untreated sample showing corrosion

\subsection{Potentiostatic and galvanostatic testing of impregnated and non-impregnated samples}

Potentiostatic and Galvanostatic testing was completed on strand samples which were centrally cast in prepackaged PT grout. (Figure 12). The sample matrix included samples with $4.5 \%$ voids as well as samples with $2 \%$ chloride contaminated grout. Impregnated and untreated samples were tested electrochemically by performing both potentiostatic and galvanostatic scans. Potentiostatic testing was completed by holding the potential of each PT tendon at $+200 \mathrm{mV}$ vs a $\mathrm{Ag} / \mathrm{AgCl}$ reference electrode for 3600 seconds. Galvanostatic testing was completed by applying a fixed current of $2.5 \mathrm{uA} / \mathrm{cm}^{2}$ and monitoring the potential over time. Impregnated samples had much greater corrosion resistance than untreated samples. (Figure 13 and 14).

Laboratory testing confirmed the corrosion resistance of the impregnation material and the ability of the impregnation material to travel along the length of a tendon, soak into the grout surrounding PT strands and to pass between all strands within the duct. 


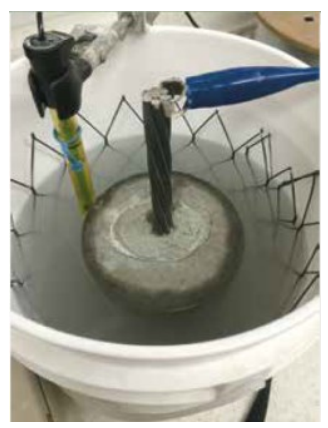

Fig. 12. Potentiostatic testing in process

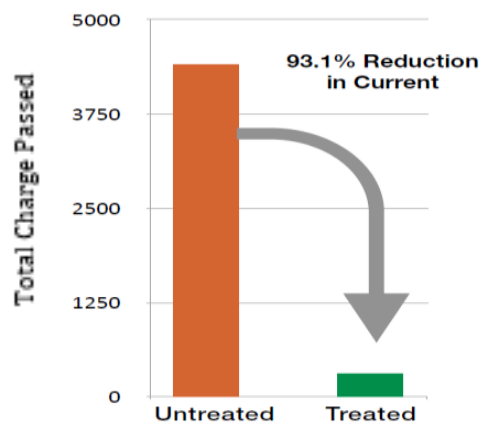

Fig. 13. Average cumulative charge passed during potentiostatic testing of post-tension strands in chloridecontaminated grout $(2 \% \mathrm{Cl})$

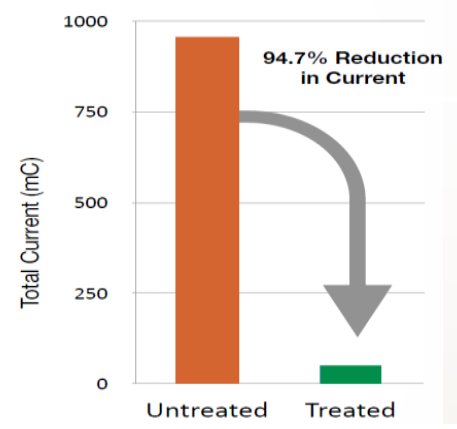

Fig. 14. Average cumulative charge passed during potentiostatic testing of post-tension strands in chloride-free grout with $4.5 \%$ void.

\subsection{Field Demonstration}

Based on the success of the laboratory work, a field demonstration project was scheduled and completed.

The demonstration project was completed on external tendons in a box girder bridge in Jacksonville, FL (I-95 / I-295 Interchange) (Figure 15 and 16). This structure was chosen for a number of reasons including:

1. Recent inspection had revealed the presence of soft grout in some tendons.

2. This structure contained external tendons which would facilitate inspection and evaluation of the effectiveness of impregnation after the work was completed.

3. All work could be completed from inside the box girder without interference with traffic.

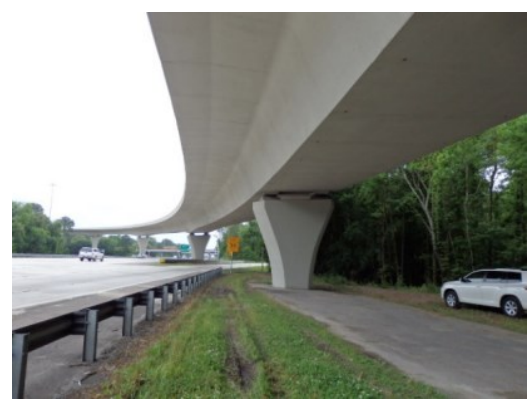

Fig. 15. I-295/I-95 Interchange, Jacksonville, FL

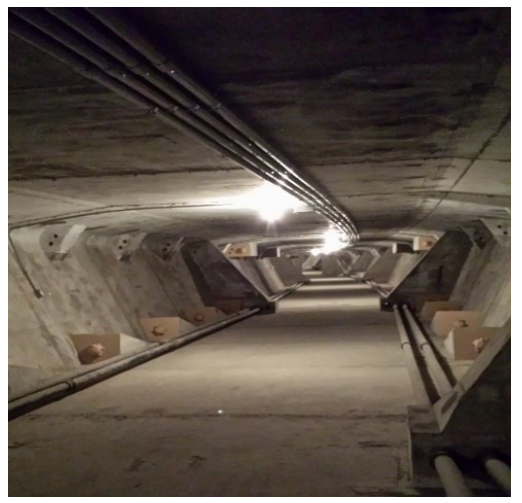

Fig. 16. Interior view. External tendons visible along bottom of box section

Impregnation of post-tension tendons was completed during the week of September 16-20, 2013. The objective of the field demonstration was to evaluate the ability of the post-tension impregnation system to impregnate bonded post-tension tendons in field structures. Some of the questions to be answered included;

- Can a tendon be impregnated from an end anchorage location?

- Can a tendon be impregnated from a mid-point location?

- How far can the material flow down the length of a tendon?

- Will the material impregnate the grout surrounding the strands?

In most locations, impregnation was completed from the anchorage end and the impregnation material was pushed through the interstitial spaces until the material reached the opposite end of the tendon (Figure 17 and 18). Tendons on this bridge varied in length from $205 \mathrm{ft}$. to $256 \mathrm{ft}$. One tendon was impregnated from the midpoint of the tendon.

As part of the evaluation process, the duct was opened in 24 locations and grout was removed to confirm the impregnation material had travelled along the length of the strands and had penetrated the grout directly surrounding the strands (Figure 19, 20, 21, and 22). 


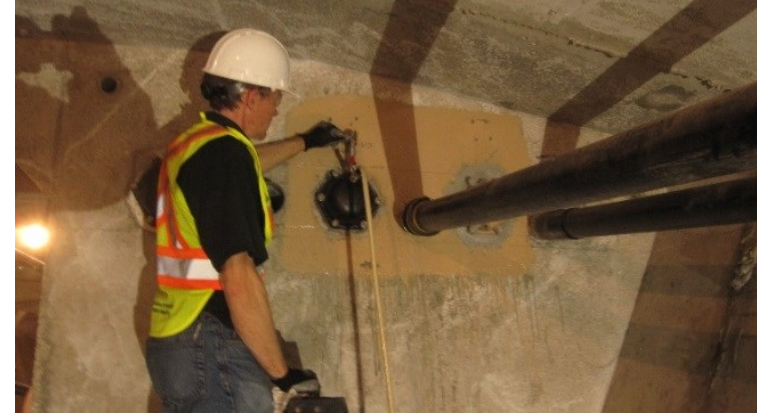

Fig. 17. Impregnation being completed from the end of a tendon

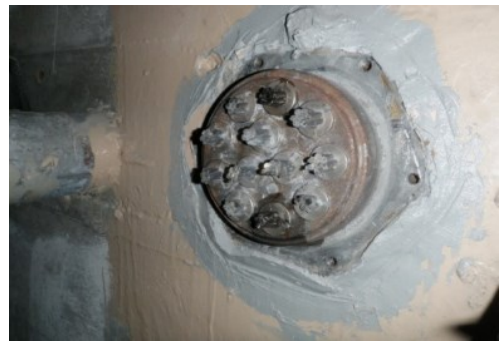

Fig. 18. Impregnation material beginning to seep out the far end of a tendon. ( $256 \mathrm{ft}$. $/ 78 \mathrm{~m}$ from point of impregnation)

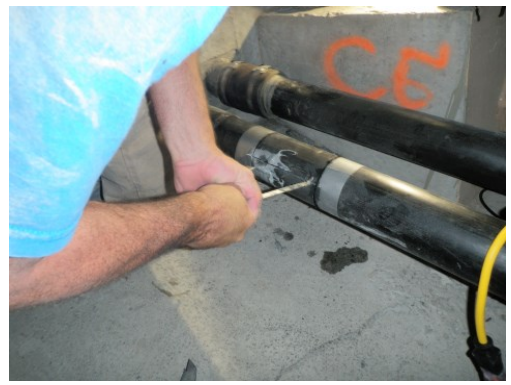

Fig. 19. Duct removal to evaluate penetration

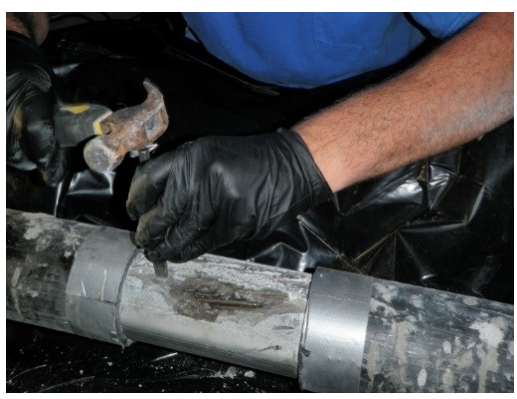

Fig. 20. Removal of grout

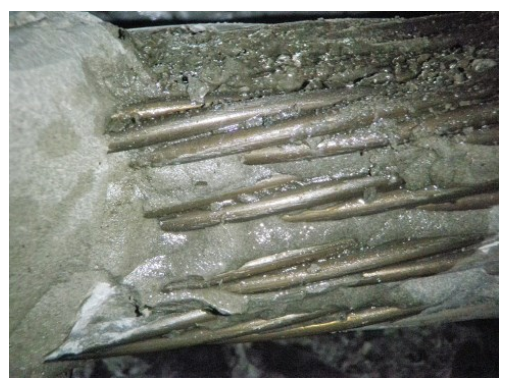

Fig. 21. Observe the level of saturation after grout removal

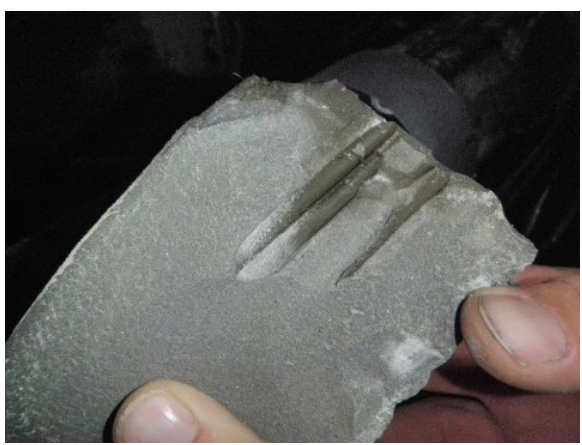

Fig. 22. Impregnation material present on the outside surface of the strands

The field demonstration verified the following:

1. The Post-Tech PTI Impregnation system is capable of impregnating the full length of 256' and 205' grouted tendons when completed from an end anchorage location.

2. The Post-Tech PTI Impregnation system is capable of impregnating up to 100 ' in each direction when completed from a mid-point location along the tendon.

3. The Post-Tech PTI Impregnation material present in an impregnated strand is capable of penetrating grout adjacent to the strand.

\section{Case study - FDOT I-4 connector in Tampa}

I-4 Connector / Lee Roy Selmon Expressway Interchange in Tampa was under construction from 2010 to 2014. Soft grout was found in tendons 7-2 T4L, 7-2 B3R, 7-2 B4R, 7-2 T5L, 7-4 T3L from spans 2 and 4 in Bridge 7 and 9-21 T4L, 9-21 T3R, and 9-21 T2R from span 21 in Bridge 9. Since soft grout has resulted in corrosion of PT tendons in other Florida bridges, Florida Department of Transportation requested the corrosion risks in these tendons be mitigated before issuing a certificate of completion for the project.

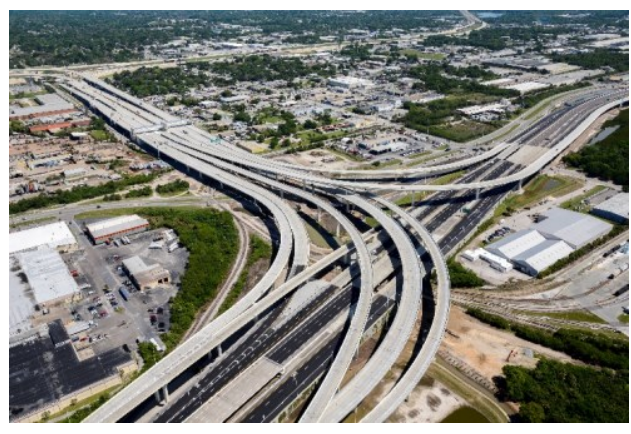

Fig. 23. I-4 Connector in Tampa, FL

\subsection{Post-tension impregnation process}

The post-tension impregnation system was connected to the end cap at one end, the impregnation material was pumped into the tendon under pressure and the material flow was monitored. When the impregnation material came out from the opposite end, the first end was sealed. 
The impregnation pump was moved to the opposite end. Material flow was monitored, and the pressure was maintained for 24 hours. Following this, the system was stopped and removed.

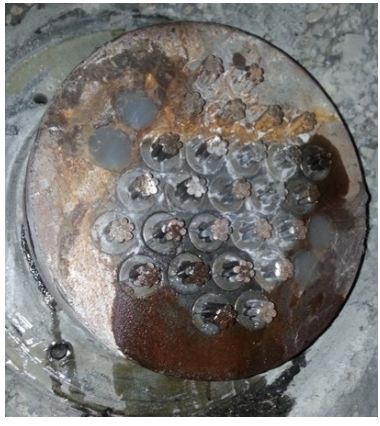

Fig. 24. PTI material beginning to appear at the opposite end of tendon 9-21 T2R

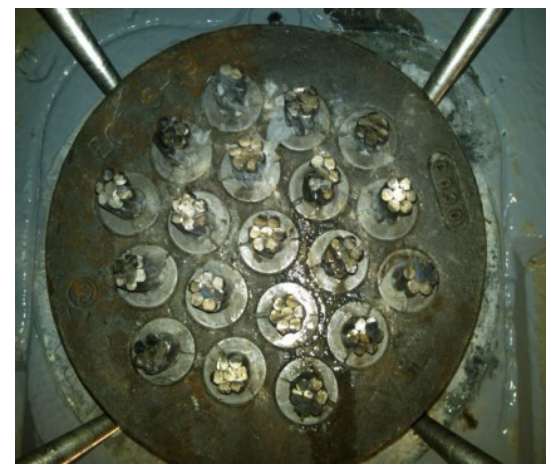

Fig. 25. Anchorage and strand tails after treatment. Note: Impregnation continues until material comes out all strands

\section{Conclusion}

Laboratory testing confirmed the corrosion resistance benefit of impregnated vs non-impregnated PT tendons.

Field testing on the I-95/295 Interchange in Jacksonville, Florida and the I-4 Connector in Tampa, Florida has demonstrated that:

- $256 \mathrm{ft}(78 \mathrm{~m})$ long grouted tendons can be impregnated from an end anchorage location. Impregnation material can be pumped up to $100 \mathrm{ft}$ $(30 \mathrm{~m})$ in each direction from a mid-point location, and

- The impregnation material is capable of coating bare sections of strand and penetrating grout adjacent to strands which are embedded in grout.

\section{References}

1. Florida Department of Transportation, (Contract Plans: State Road No. 8 [I-10] David Bogan State Road No. 8 [I-10] over Esambia Bay, 2012)

2. K. Bergum, T. Risher, Evaluation of a Silicon Based Polymer Corrosion Inhibitor for Post-Tensioned Tendons, 2017) 